\title{
Factor Rents, Sole Ownership and the Optimum Level of Fisheries Exploitation ${ }^{* \dagger}$
}

In the literature of fisheries economics there is a noticeable preoccupation with the phenomenon of resource rent dissipation. The common property nature of most fishery resources-with the attendant free entry of labour and capital-gives rise to 'problems' of 'overfishing'. If at any given level of fishing effort the resource should yield a rent to the marginal operator, additional factor inputs of labour and capital will be attracted that will depress the catch per unit of effort and lower returns to all operators. This process will continue until the revenue per unit of fishing effort is reduced to the level of its marginal opportunity cost. Thus the rent attributable to the resource, that formerly accounted for the excess of revenue over marginal opportunity cost, is eliminated.

Gordon, in his seminal article that launched the theory of fisheries economics, identified optimum utilization with maximization of rent. His analysis held that at " . . the optimum intensity of effort . . the resource will ... provide the maximum net economic yield ... which can be regarded as the rent yielded by the fishery resource". ${ }^{1}$ In accordance with this perception economists have been inclined to suggest institutional measures that would prevent or reduce 'overfishing' and retain or recapture all or some of the rent that a fishery could yield. Commonly, the proposed remedies have involved some regime of single or central management based on sole ownership or control of the resource, that would limit labour and capital inputs. ${ }^{2}$

The purpose of this article is not to deny the essential correctness of the existing formal analysis regarding rent dissipation, so much as it is to question the weight of its importance. This paper will attempt, by the application of conventional criteria of welfare maximization, to balance the consideration of resource rent with that of competing social benefits which may derive from the exploitation of a fishery. In so doing the analysis will focus on the significance of consumers' surplus and producers' surplus, the latter in the form of rent (or 'quasi' rent, if one prefers) accruing to factors other than the fishery 
resource itself. Commentary will also be given on major implications for resource management policy in respect of resource ownership forms.

This paper will be limited to a steady state analysis following the models used in articles by Turvey and Copes. ${ }^{3}$ It will abstract from 'second best' problems. It will assume optimal techniques and fixed combinations of factors other than the fishery resource. Externalities will not be considered, except where they follow directly from bio-economic interaction through variation in the level of fishing effort. The income redistribution effects of price changes and factor income changes will be ignored in the process of optimizing welfare, Total social benefit (in gross terms), or social 'revenue', will be measured by the maximum consumers are prepared to pay for goods-in this case fish. Social cost will be measured in terms of the opportunity costs of labour and capital.

The analysis that follows will be illustrated in conventional price/output diagrams. The long-run supply curve of a given fishing industry ( $S$ in Figure 1 ) is the locus of steady state output equilibria

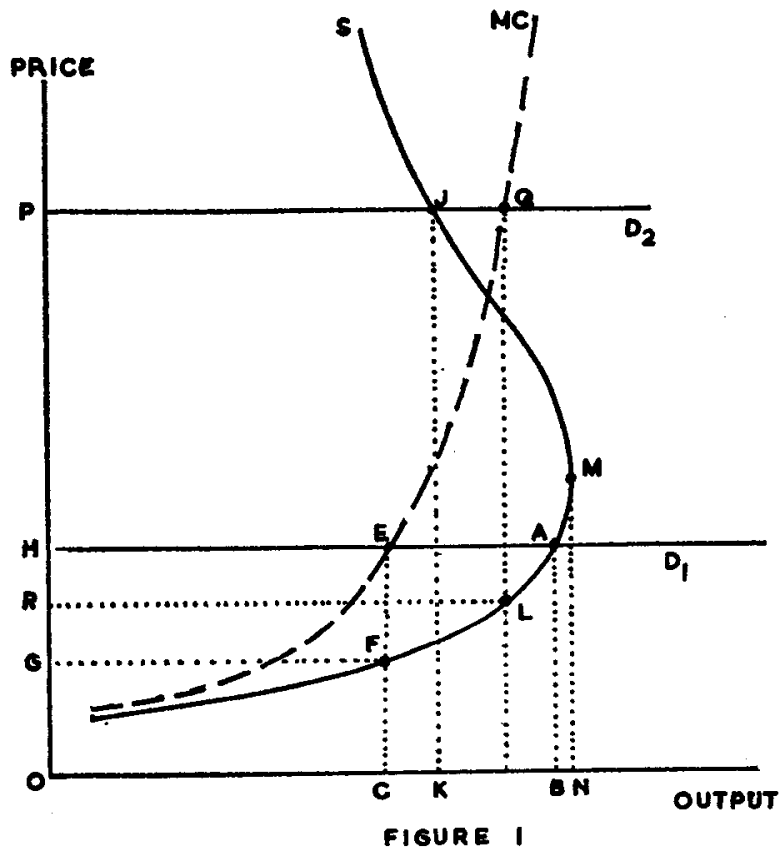

at various price levels.4 It shows, for each level of output in the fishery concerned, the unit cost of production, as determined by the 
marginal opportunity costs of labour and capital, being the factors employed other than the fishery resource itself. For expository purposes initially it will be assumed that all fishing units (consisting of fixed combinations of labour and capital) have equal opportunity costs, and are of equal efficiency, so that their costs per unit of output will be equal. In other words, initially it will be assumed that there are no intramarginal fishing units with opportunity costs lower than those of marginal fishing units. Accordingly the supply curve will measure both the average social cost and the average private cost of fishing units. The assumption of equal opportunity costs will be removed later in the paper. Typically this supply curve will be backward bending, the maximum abscissa measuring the maximum sustainable yield of the fishery $(O N)$. The various points on the supply curve correspond to various levels of fishing effort. Starting from a low level of effort at the lower left end of the curve, successively higher levels of effort are represented by successively higher points on the curve. In moving upwards along the curve through points representing successively greater effort per time period, the corresponding output measured on the horizontal axis initially will increase (though at a diminishing rate) until the maximum sustainable yield is reached (at $M$ ), after which further increases in effort will result in successively smaller total outputs represented by points on the backward slope of the curve. Each higher point on the supply curve represents a higher level of sustained fishing effort as well as a lower total fish stock in equilibrium.

To start with, the rudiments of Gordon's theory of fisheries economics will be translated into a price/output diagram as shown in Figure 1. Assuming a perfectly elastic demand (i.e., for a relatively small fishery contributing to a relatively large market) and a regime of free entry, the demand schedule $D_{1}$ will produce a long-run equilibrium at $A$ with output $O B$ per time period. As $A B$ measures both unit cost and unit revenue, no surplus is earned: the resource yields no rent. If a curve $(M C)$ is drawn marginal to the supply curve (which here is the average social cost curve), a socially optimum output level $(O C)$ may be identified at $E .^{5}$ This output will be achieved by limiting fishing effort to the level represented by point $F$ on the supply curve. At this point a maximum net social benefit $(E F G H)$ may be obtained, constituting the difference between total (social) revenue $(E C O H)$ and total (social) cost (FCOG). This net benefit is the rent yielded by the resource. 
In the foregoing presentation $O C$ measures the optimum sustainable yield of the fishery in terms of an economically defined social optimum. Accordingly any level of sustained fishing effort higher than that represented by point $F$ on the supply curve constitutes 'overfishing' in economic terms. However, the biological potential of the fish stock permits physically a larger sustainable yield-with a maximum of $O N$. A sustained effort higher than that given by point $M$ on the supply curve will result in a smaller sustained yield being taken from the fish stock and would thus constitute 'overfishing' in biological terms (as well as economic terms). The demand given by schedule $D_{2}$ would lead, in an open entry fishery, to overfishing in both economic and biological terms. With equilibrium at $J$, the sustainable yield would be equal to $O K$, while unit revenue of $J K$ would be entirely absorbed by unit costs. However, if by entry limitation fishing effort would be held back at $L$ (which would bring demand and marginal cost in equilibrium at $Q$ ), a maximum rent of $P Q L R$ could be realized.

\section{II}

By assuming perfectly elastic demand, Gordon's analysis avoided consideration of consumers' surplus in determining the socially optimum level of output of a fishery. In Figure 2 that assumption

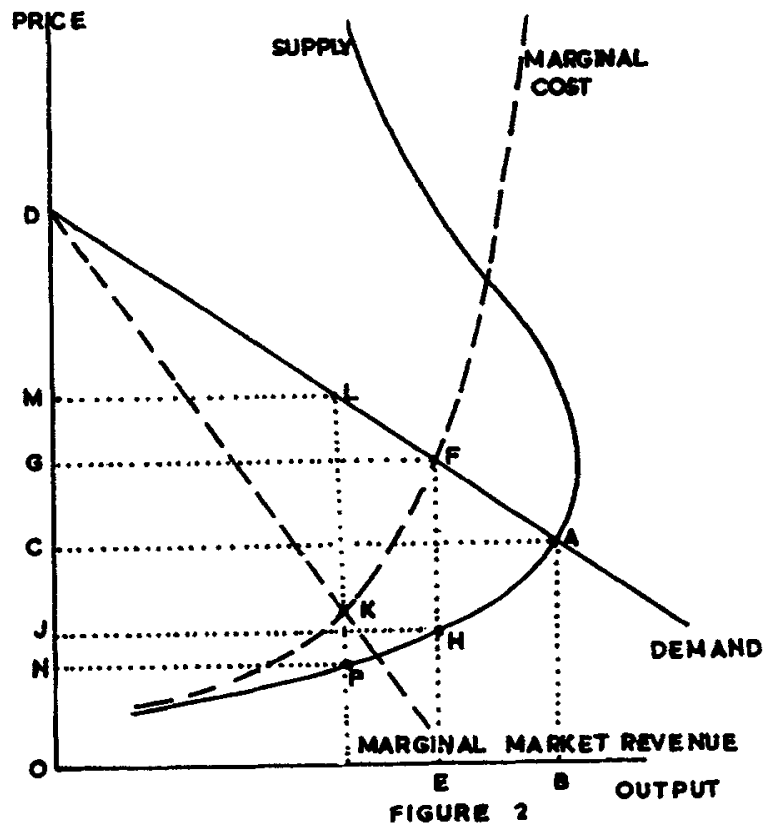


has been relaxed. In this case the output of the fishery concerned is not marginal to the market, so that any perceptible change in output will affect the amount of consumers' surplus generated. With free entry the competitive equilibrium established in the fishery at $A$ will result in an output of $O B$. generating a consumers' surplus of $A C D .^{6}$ In this instance the market revenue of the fishery $(A B O C)$ is fully absorbed by social cost which equals the private opportunity costs of fishing units.? The consumers' surplus, being in excess of market revenue, and thereby in excess of social cost, represents a net social benefit. It is possible, however, to interpose between market revenue and the cost of employing fishing units a return to the resource in the form of rent, which would equally constitute a net social benefit. The socially optimum output, then, must maximize the combined total of rent and consumers' surplus. The socially optimum output, of course, will be found at the point where marginal social cost and marginal social revenue are equal. In Figure 2 the supply curve has already been identified as an average social cost curve, with a matching marginal curve. The demand curve is a marginal social revenue curve, measuring as it does the addition to total social revenue for each additional unit of output. The socially optimum output now is found at $F$ and maximum net social benefit is given by consumers' surplus $(F G D)$ plus rent $(F H J G){ }^{8}$ In moving from output $O B$ to the optimal $O E$ the price that will clear the market rises from $O C$ to $O G$. This will bring with it a reduction in consumers' surplus, which is more than offset by the gain in rent. The latter could be acquired by the state in the form of production-related taxes or license fees (and possibly redistributed to consumers), or it could accrue to the group that is privileged to prosecute the restricted fishery.

The granting of sole ownership rights in respect of a fishery is often advocated as one way of approaching optimum exploitation. ${ }^{9}$ Whether the owner is the state or a private agency, it is argued, the owner would have an interest in maximizing the return from the fishery. The dissipation of rent by excessive effort that occurs with free entry could be prevented. The consideration of consumers' surplus, however, does raise the question whether a sole owner would be correctly motivated toward the achievement of a socially optimum level of exploitation. In particular, there may be a difference in the respective motivations of public and private agencies. A private firm, granted the sole right to exploit a fishery, presumably would have no interest in consumers' surplus. To such a firm the demand 
curve would not be a marginal revenue curve but an average revenue curve. A corresponding marginal ('market') revenue curve may be determined. But as the private firm would have to pay for capital and labour inputs at the rate of the opportunity costs of marginal units, the supply curve would remain the average cost curve for the firm. The intersection of the marginal market revenue and marginal cost curves at $K$ in Figure 2 shows the maximum rent obtainable by the private sole owner as $L M N P$. But maximizing rent and consumers' surplus together is bound to yield a greater net social benefit than maximizing rent alone (except where the demand curve is perfectly elastic, when consumers' surplus will be zero). A public sole ownership agency, if instructed to observe marginal cost pricing, would operate at the socially optimum output level of $O E$, charging consumers a price of $O G$ and maximizing the combined net social benefits of consumers' surplus $(F G D)$ and rent $(F H J G)$.

\section{III}

Turvey observed that the "maximum gain" that may be derived from the exploitation of a fishery contains three elements. ${ }^{10}$ Not only consumers' surplus and resource rent are involved, but also producers' surplus. The latter consists of the rent that intramarginal inputs of labour and capital enjoy to the extent that their opportunity costs per unit of output lie below those of the marginal inputs of these factors. ${ }^{11}$ For to that extent intramarginal factor inputs will receive revenue in excess of their opportunity costs; at least if there is no price discrimination and all factor inputs are remunerated according to the opportunity costs of the marginal inputs. In much of the theoretical literature of fisheries economics the consideration of producers' surplus is avoided by assuming the equality of market cost and social cost and by assuming the equality of the cost of all units of fishing output. Such were also the assumptions of the foregoing discussion in this paper. The consequences of the removal of these simplifying assumptions will now be explored.

There are generally two reasons for which intramarginal factor inputs may have opportunity costs below those of marginal factor inputs in a fishery. In the first place, differences in alternative employment and income opportunities for various fishermen and their gear may exist. But what is probably far more important is the difference in efficiency of various fishing units. To accommodate these phenomena in the model of this paper the following understanding is needed. Inputs of labour and capital will be considered combined into units of fishing effort of equal productive capacity. 
Such units of fishing effort then will be equal in terms of amount of catch produced, but not necessarily in terms of amount of equipment used, numbers of crew members employed, extent of fishing time or level of operating cost. Translated into a practical example this means that if one vessel-crew combination produces twice as much fish as another, the former will be considered to represent two units of fishing effort as against one unit for the latter. This will be so even where the vessels would be identical physically and have equal numbers of crew members with individually equal opportunity costs, equal hours of fishing time and equal operating expenses. In such a case the opportunity costs in absolute terms for the two vessel-crew combinations would be the same. But for the former vessel they would be distributed over two units of fishing effort and would therefore be shown at half the level of the opportunity costs for the one unit of fishing effort represented by the latter vessel.

Close observation of catch statistics for many fishing fleets reveals considerable variation in landings for different vessels, even where these vessels represent roughly equal capital investments and where they are manned by crews of equal size. The catch variations, then, are a prima facie indication of considerable differences in opportunity costs per unit of fishing effort, as defined above. The differences in catch result in part from chance factors-fishermen's luck. For another part they result from variations in vested positions, such as port location, traditional or inherited rights to prime berths for the setting of gear, or similar rights obtained by other non-market means of allocation. Some of these considerations, strictly speaking, are questions of partial ownership rights. But for many fisheries the major differential in productivity, and thus in opportunity costs, simply results from differences in fishing skill and knowledge among various fishing crews. A selection process often takes place that maintains or widens these differences. Fishermen are commonly compensated on a share-of-catch basis, which means that the more efficient a crew is, the higher will be the rewards for all its members. Multiple vessel fishing companies desirous of retaining or attracting the most efficient captains and crew members, commonly allow the best captains first choice in picking the best crew members. Thus the differential in overall efficiency between vessels is maintained with resulting large differences between 'high-liners' and vessels at the bottom of the efficiency scale.

Economists looking from afar at the problems of low productivity that appear to characterize most of the fishing industries of indust- 
rially advanced nations, are often given to generalize that all fishermen earn little at their trade. In his leading article Gordon remarked: "By and large, the only fisherman who becomes rich is one who makes a lucky catch or one who participates in a fishery that is put under a form of social control that turns the open resource into property rights". ${ }^{12}$ This notion has confirmed economists in their belief that they have found the explanation of this poverty in the peculiar common property nature of the fishery that leads to the dissipation of the resource rent. But the economists' notion is challenged by many practical men in the fishing business who know that significant numbers of fishermen and fishing company operators earn large incomes and that some gain small fortunes. They also know that the high earners, who operate competitively in fisheries with unrestricted entry, do not depend on luck, but perform consistently at much higher levels of efficiency than do their rivals.

The difference in a fishery between marginal opportunity costs, which match revenue, and the lower opportunity costs of intramarginal fishing units is a form of rent (or 'quasi' rent). This rent is the substance of the producers' surplus. It is not attributable to the nature of the resource as such, but is primarily related to the efficiency of the intramarginal fishing units. Nevertheless, this rent must be considered a feature of the fishery as the efficiency from which it derives is an efficiency of labour and capital that is peculiar to their specific application to the fishery resource. The same units of labour and capital may or may not have any efficiency advantage in alternative employment. A good fisherman may not be any good at any other trade. The notion that fisheries allowing free entry yield no rent therefore requires qualification, for considerable rents may be earned by intramarginal factor units specifically as a result of their employment in the fishery. The literature of fisheries economics has tended to ignore the significance of this rent, perhaps because it was thought of as a matter of small differences in terms of alternative employment opportunities instead of large differences in terms of operational efficiency.

\section{IV}

The introduction of producers' surplus into the analysis requires the differentiation of social cost from market cost. This is illustrated in Figure 3. The $A M C$ curve represents the supply curve described in previous figures. It measures the average market cost at each output level as determined by the opportunity costs of marginal units of fishing effort. For a competitive fishery this is the operational 


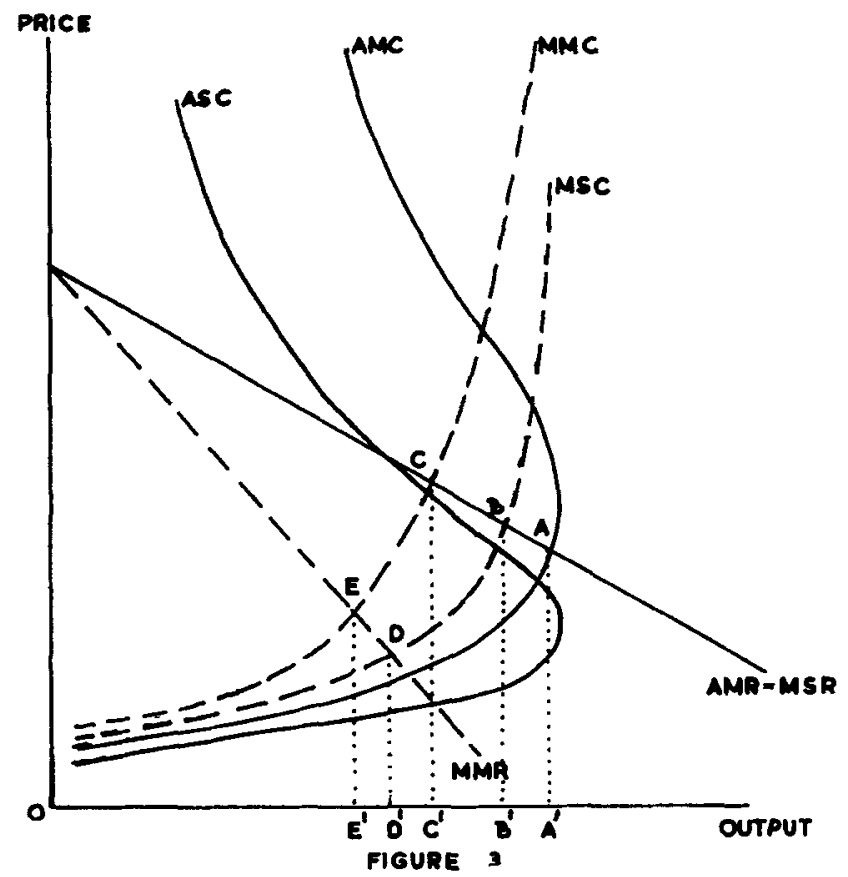

long-run supply curve that will indicate output equilibria for various price levels. The $M M C$ ('marginal market cost') curve has been drawn marginal to the $A M C$ curve. It measures marginal cost per unit of output to any operator possessing sole ownership rights in respect of the fishery resource (e.g., a state fishing monopoly or a private fishing company with an exclusive licence), but hiring other factors (labour and capital) at rates determined by the marginal opportunity cost of fishing effort. The $A S C$ ('average social cost') curve is obtained by subtracting the average producers' surplus from the average market cost and thus represents the average opportunity cost per unit of output for labour and capital. The $M S C$ ('marginal social cost') curve is drawn marginal to the $A S C$ curve. ${ }^{13}$ Also in Figure 3 a demand curve is shown. It functions both as an 'average market revenue' ( $A M R$ ) curve and a 'marginal social revenue' (MSR) curve, in so far as it measures at any output the additional value enjoyed by consumers at the price the marginal buyer is prepared to pay. A 'marginal market revenue' (MMR) curve has been drawn marginal to the demand curve to show the marginal revenue enjoyed by sellers collectively (or by a monopoly seller) for the output of the fishery. 


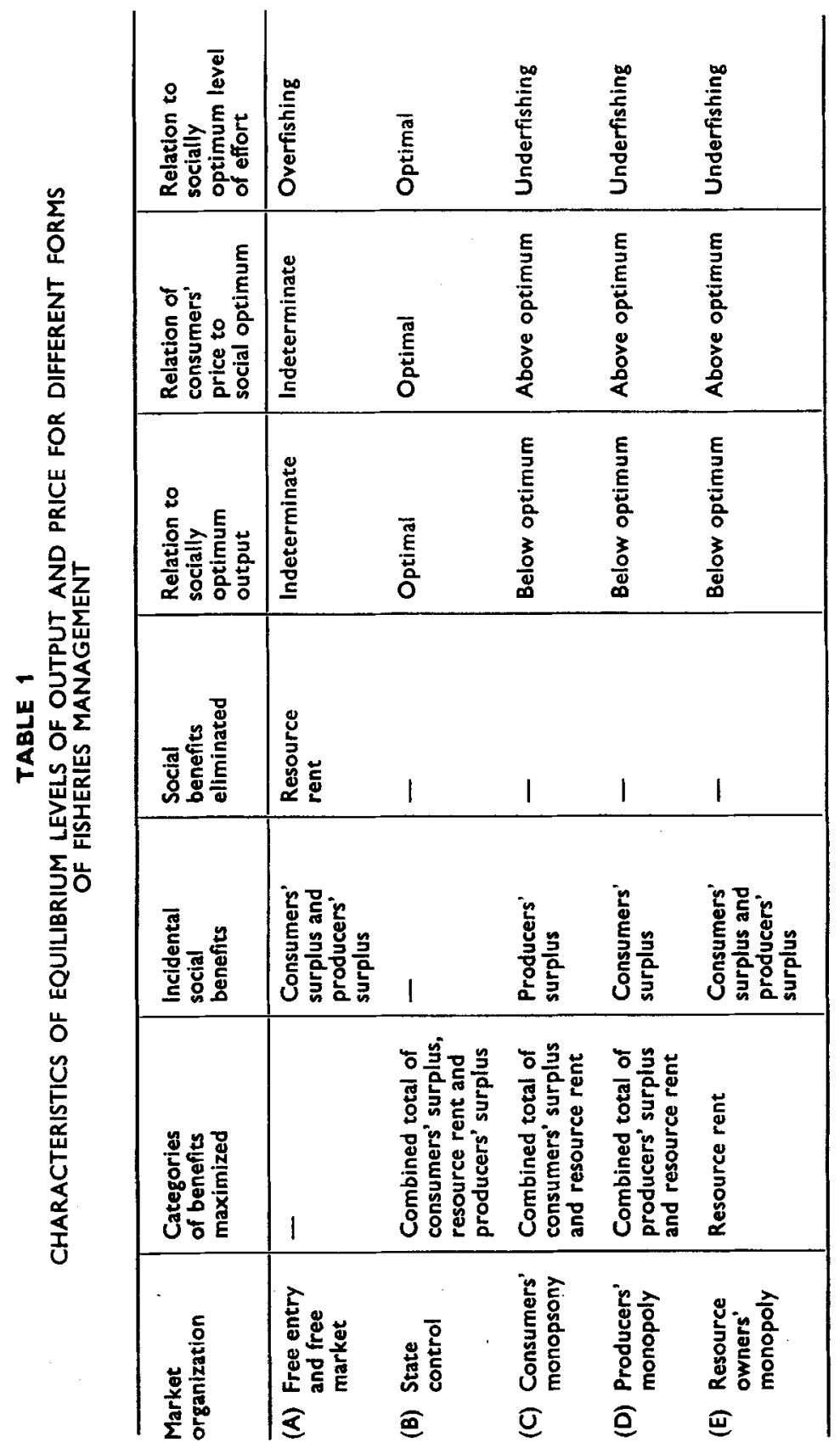


동
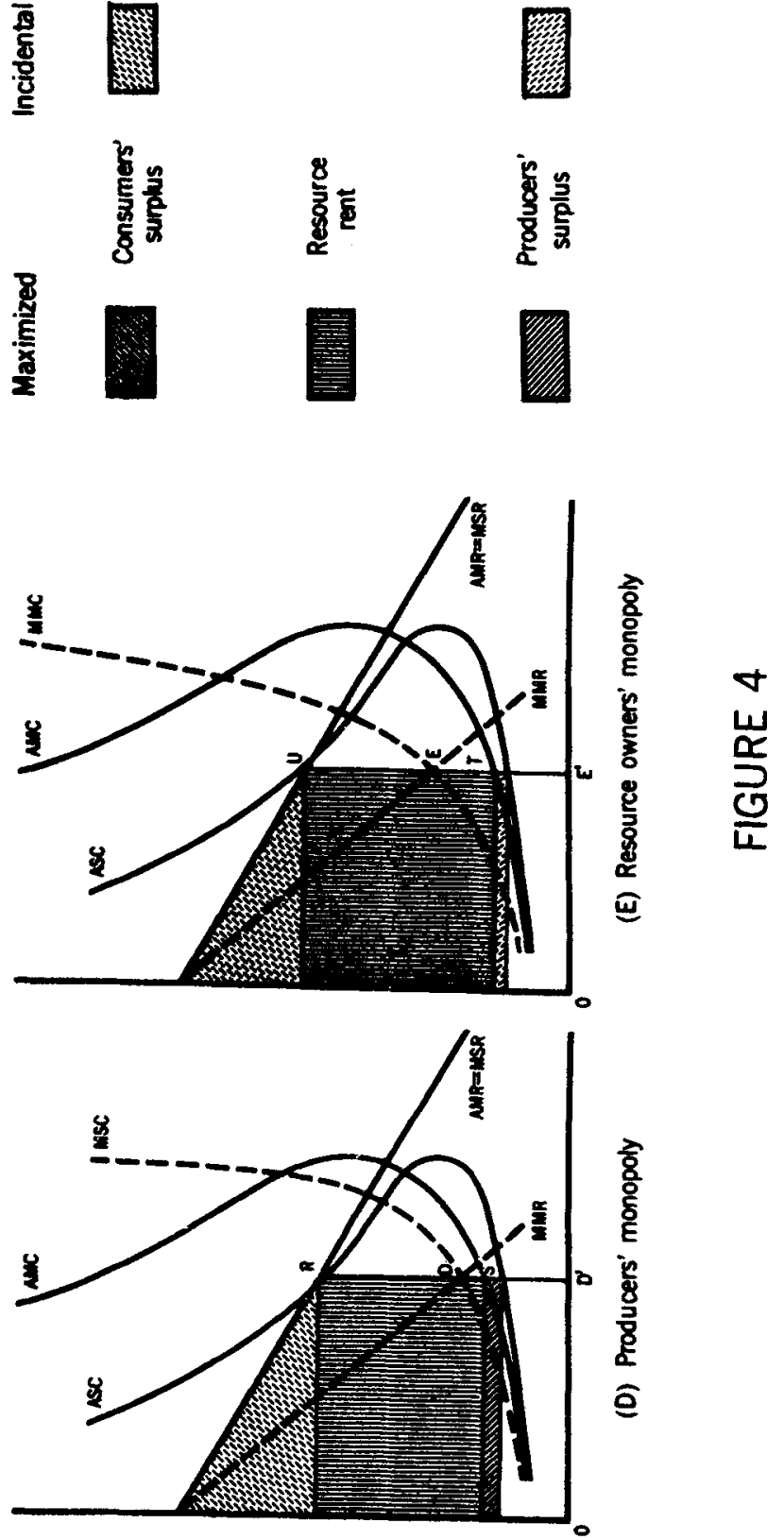

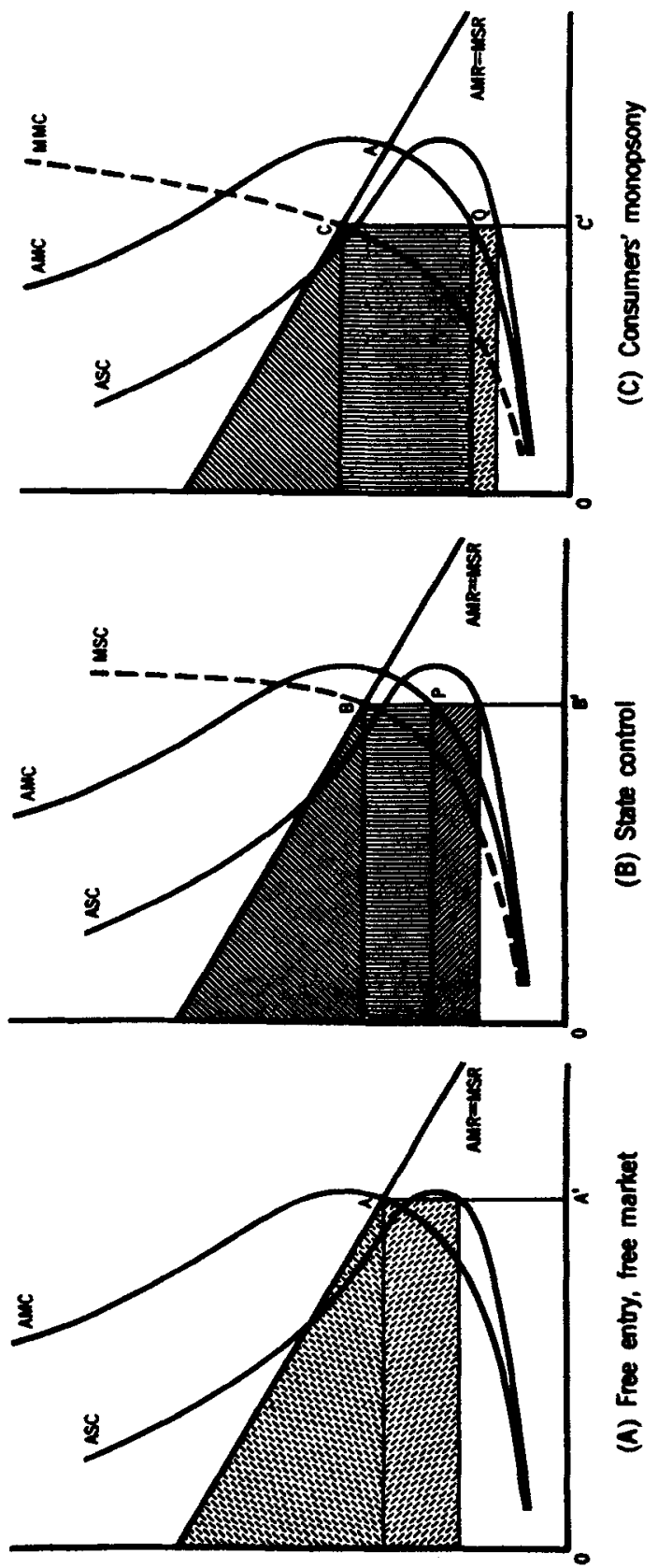
Figure 3 may now be used to identify the different equilibrium positions that relate to control over the fishery resource by various interest groups. Generally, three distinctly different interest groups may be recognized. Consumers would benefit from a regime that would maximize consumers' surplus. Private owners of the fishery resource would want to maximize resource rent. Finally, the owners of other factors (labour and capital) would profit from the maximization of their factor rents in the form of producers' surplus. Maximizing equilibrium positions are identified by the intersection of appropriate marginal revenue and marginal cost schedules. Having identified two marginal revenue and two marginal cost schedules, the permutations permit four distinct equilibrium positions. Three of these represent, in turn, the primacy of each one of the three interest groups, while the fourth represents the 'optimum' position of social control in the joint interest. There is also a fifth equilibrium position that is non-maximizing. It results from the free interplay of market forces. Major characteristics of these five positions have been summarized in Table 1, while Figure 4 illustrates graphically the relationship of the three categories of social benefits in each equilibrium position. Further comment on the five equilibrium positions follows:

(A) The intersection of the market demand and supply curves (A) produces an equilibrium output $O A^{\prime}$ that will apply in an open entry fishery supplying a competitive market. This is the laissez-faire position that is approached in most common property fisheries. It results in the dissipation of rent through overfishing, but allows for incidental amounts of consumers' and producers' surplus. Price and output equilibria may be above or below the socially optimum levels, depending in part on whether the equilibrium is located on the forward or backward slope of the supply curve.

(B) In terms of the definitions and assumptions of this paper, the socially optimum equilibrium position is given by the intersection of the marginal social revenue and marginal social cost curves at point $B$ in Figure 3. This position allows for the largest total net social benefit by maximizing the combined total of consumers' surplus, resource rent and producers' surplus. It requires centralized control (presumably by government) to limit output to $O B^{\prime}$ by holding fishing effort to the level determined by point $P$ on the supply curve, as shown in Figure $4(B)$. The price charged to consumers will be $B B^{\prime}$, while options remain open for disposition of the rent. 
(C) If consumers by collective action would acquire monopsony control over the market for the output of a fishery, they would be in a position to capture the rent available from the resource. They could then maximize the combined total of consumers' surplus and rent to their own advantage. In this category one could think of a consumers' co-operative as a monopsonist purchasing the entire catch from a group of competing fishermen. The optimum output for the monopsonist co-operative would be determined by the intersection of the $M S R$ and $M M C$ curves, shown at $C$ in Figure $4(C)$. The monopsonist concerned with maximizing consumers' benefits would be guided by the marginal social revenue schedule that relates to values enjoyed by consumers, rather than by the marginal market revenue schedule that would relate to money receipts by producers. Conversely, its unconcern for the welfare of producers would cause it to be guided by marginal market cost that relates to the cost of its purchases, rather than by the marginal social cost that relates to the opportunity costs of producers. To appropriate the resource rent the co-operative would have to use its monopsonist power to hold its buying price down to the opportunity cost of marginal fishing units as measured by $Q C^{\prime}$. It would then capture a rent of $Q C$ per unit of product. An incidental amount of producers' surplus would still accrue to intramarginal fishing units. In disposing of the rent, the co-operative would have to avoid paying dividends to its members in proportion to the amount of fish purchased by these members. For this would effectively lower the price of fish to members, causing them to increase purchases. The culmination of this process would be the establishment of equilibrium at $A$ in the free market position where rent would be dissipated. The co-operative would thus lose the advantage of its monopsonist position and the total benefits accruing to it and its members would diminish. If the co-operative were confronted in the market not by a number of competing fishermen, but by a monopolist seller, the division of the rent between monopsonist buyer and monopolist seller would be indeterminate. Another example of a monopsonist buyer maximizing consumers' surplus plus resource rent could be a government marketing monopoly selling fish in a national market and contracting with foreign operators to deliver the fish. The government, presumably, would have an interest in capturing a maximum of consumers' surplus and rent for its citizens, but would have no interest in the foreign producers' surplus. 
(D) The case of the producers' monopoly is symmetrical to that of the consumers' monopsony. A co-operative or marketing association of all operators in a fishery (or a single operator representing all inputs in a fishery), when facing a multiplicity of buyers, could appropriate both resource rent and producers' surplus. The optimum position for the producers' monopoly as indicated in Figure $4(D)$, would be determined by the intersection of the $M S C$ and $M M R$ curves at $D$. The monopolist's concern for producers' incomes would be guided by the marginal social cost schedule that is related to the opportunity costs of producers. But on the sales side the marginal market revenue schedule would give the appropriate guidance, demonstrating unconcern for the social revenue of consumers. The monopolist seller would want to set the price at $R D^{\prime}$ to appropriate a rent of $R S$ per unit of product. This would maximize the resource rent and producers' surplus accruing to the producers' monopoly, while leaving an incidental amount of consumers' surplus.

(E) The final case to be considered is that of sole ownership of a fishery resource where ownership is divorced from both consumer interests and the interests of other producing factors, i.e., capital and labour. One could think of a 'landowner' (water owner in this case) renting the right to exploit a fish pond or oyster bed. The resource owner, in charging the maximum rent for which he can find takers, will cause an equilibrium output to be established at the level for which marginal market revenue and cost coincide. This is shown at point $E$ in Figure $4(E)$. Incidental amounts of consumers' surplus and producers' surplus will accrue. Marginal operators will find that they can just cover their opportunity costs of $T E^{\prime}$ per unit of output by charging the market price of $U E^{\prime}$ and meeting the rent payment of $U T$ per unit of output.

There are some common features of the three cases of private sole ownership or control of the resource-i.e., cases $(C),(D)$ and $(E)-$ when contrasted with case $(B)$, which represents social control in the general interest. The private sole ownership arrangements all result in higher prices and lower outputs. They represent cases of 'underfishing'. Indeed, a restriction of output is what one would expect in monopoly situations. In each of these cases only one or two of the three categories of social benefit are maximized, so that the total net social benefit achieved is less than that of the full social control case. 
Socially the least profitable is the case of the private resource owners' monopoly which maximizes only one category of social benefit, viz., resource rent. Of the four cases it provides for the lowest output and the highest price.

It is clear that the equilibrium position in the competitive market with free entry to the fishery will be non-optimal. Resource rent will be dissipated. But there is nothing in the analysis to suggest that the incidental accretions of consumers' and producers' surplus in this case could not be in excess of the total net social benefits generated under any of the private sole ownership arrangements. A priori there is then no reason to advocate as a matter of policy the granting of private sole ownership rights in lieu of free entry to the fishery. However, in the case where a fishery can be divided into a large number of small fishing grounds that are not interacting biologically (perhaps in an oyster fishery), separate sole ownership rights might be given in respect of individual grounds. Owner-operators would have an interest in maximizing on each ground the producers' surplus plus rent. If they were then competing with the sale of their output in a perfectly competitive market, they would not detract from consumers' surplus. Under these circumstances fishermen would resemble wheat farmers, maximizing returns from their individual holdings while selling in a perfectly competitive market. In that case sole ownership would be compatible with the social optimum and would thus be superior to free entry.

The analysis of this article has focused on the significance of consumers' and producers' surpluses in determining the socially optimum level of fisheries exploitation. There are two points that bear particular note as they run counter to past emphasis in the literature : (1) Rents yielded by fishing activity include rents to intramarginal inputs of labour and capital, which are not dissipated by unlimited entry to the fishery, and which could be of equal or greater importance than resource rents. (2) Management of a fishery by a regime of private sole ownership is generally non-optimal from a social standpoint and is not inherently superior to unlimited entry.

There is nothing in this paper to suggest that the social optimum does not require some restraint on entry to the fishery. But its major conclusions tend to diminish the weight of importance that 
has been attached to such entry limitation. They also suggest that limitation through private sole ownership arrangements, which is often advocated, in the general case would overshoot the mark and result in underfishing. The analysis then gives reason to concede some ground to those biologists and government administrators who are sceptical of economic theory and are intuitively drawn to the biological criterion of the maximum sustainable (physical) yield. It is clear that the fishing effort required for a social optimum that maximizes consumers' and producers' surpluses along with resource rent, will come closer to the fishing effort of free entry and of maximum sustainable yield, than will the more strictly limited effort that results from maximization of resource rent only.

The foregoing analysis has some practical implications for resource management policy. In the industrially advanced nations, generally, a serious degree of overfishing tends to take place. Improved technical efficiency coupled with low mobility of labour and capital out of the industry has increased pressure on the fishery resource while it has tended to depress factor incomes. This in turn has pressured governments into subsidizing the fishery. However, an increasing awareness of the nature of the problem has caused some governments to start imposing entry limitations on the fishery-at least in cases where a fishery comes under a single national jurisdiction or under an international treaty arrangement. In deciding how far to proceed with entry limitation it behoves governments not only to pursue an increase in resource rent, of which the capacity to raise license fees would be a measure. It is also necessary to watch for the retention of producers' surplus, particularly where the low incomes of producers are so central to government concern. The greater the level of fishing effort, of course, the larger will be the number of intramarginal fishing units that may earn a producers' surplus (though the total amount of producers' surplus will not necessarily increase). From the analysis it should be clear then that the optimal entrance limitation is less stringent than what the single-minded pursuit of resource rent capture would require.

The execution of a resource management policy along the lines suggested above naturally will encounter problems. The enforcement of entry limitation where freedom of entry has traditionally prevailed will likely entail political and social difficulties in phasing out surplus labour and capital. In determining the appropriate level of limitation there is also the problem of calculating the marginal social cost schedule-or the average social cost schedule from which it may be 
derived. But the calculation of a reasonably realistic approximation of such a schedule should not be beyond the wit of economists and statisticians, when they do not blanch at carrying out cost-benefit analyses that require them to estimate the intangible values of recreation or the multifarious externalities of pollution. (These latter matters could indeed intrude into the social cost calculations of some fisheries). The critical ingredients of social cost calculation in respect of a fishery would seem to consist of an estimation of the value of alternative employment opportunities for factors engaged in the fishery and a measurement of the varying efficiency of different fishing units. These tasks should not be beyond the survey capability of the sophisticated research units of present day government agencies.

Parzival Copes.

Simon Fraser University. 


\section{NOTES}

* This article is a by-product of a research project regarding the Newfoundland fishing industry supported by the Canada Council.

$\dagger$ Manuscript received 13/7/71.

1. H. Scott Gordon, 'The economic theory of a common property resource: the fishery,' Journal of Political Economy Vol. 62, April 1954, p. 130.

2. An early important contribution is Anthony Scott, "The fishery: the objecttives of sole ownership,' Journal of Political Economy Vol. 63, April 1955, pp. 116-24.

3. Ralph Turvey, 'Optimization and suboptimization in fishery regulation,' American Economic Review Vol. 54, pp. 64-76. Parzival Copes, 'The backward-bending supply curve of the fishing industry,' Scottish Journal of Political Economy Vol. 17, February 1970, pp. 69-77.

4. Copes, op. cit. p. 71.

5. The MC curve drawn matches only the forward sloping portion of the supply curve. One could devise a marginal curve matching the backward sloping portion, which would measure increases in total cost with each reduction in output. However, the MC curve is needed only to assist in determining the optimum level of output. As is explained below, no optimum output position will be associated with any point on the backward slope of the supply curve, so that no matching $\mathrm{MC}$ curve need be considered.

6. The consumers' surplus may be shown graphically as (a) the area above the level of market price and below the marginal social revenue curve, or (b) the rectangular area inscribed between the level of market price and the average social revenue curve. While the latter method would have provided for symmetry in presentation (rectangular areas inscribed between average curves are used for resource rent and producers' surplus), it would have required the drawing of an additional curve (average social revenue), adding to the complexity of the graphs. Therefore the former method of presentation has been used for consumers' surplus.

7. It is assumed throughout this article that there is no market discrimination, so that all units of output are sold at the same price. The 'market revenue' therefore will always be given by the product of output and the uniform price established at the relevant point on the demand curve.

8. Ibid. p. 76. In a similar situation in that article the rent generated was inaccurately identified as "maximum". It is, of course, rent plus consumers' surplus that is maximized.

9. Cf. Scott, op. cit. p. 117, who states: ". . I wish to show that long-run considerations of efficiency suggest that sole ownership is a much superior regime to competition ...."

10. Op. cit. p. 71.

11. Various definitions of producer's surplus are possible and various components may be specified. Cf. E. J. Mishan, 'What is producer's surplus?,' American Economic Review, Vol. 58, December 1968, pp. 1269-83. Mishan proposes that reference to producers' surplus be dropped and that various forms of rent be defined instead. In this article producers' surplus is considered synonymous with the rent enjoyed by intramarginal units of capital and labour to the extent that their opportunity costs fall below those of marginal units of these factors.

12. Op. cit. p. 132.

13. It may be noted that the MSC curve will lie below the MMC curve,because increases in social cost will be less than increases in market cost to the extent that additional intramarginal rents accumulate. The MSC curve will be above the AMC curve. The latter measures at each output only the opportunity costs per unit of output for marginal fishing units. The former measures (per unit of output) these opportunity costs of marginal fishing units plus the increase in total opportunity costs related to the decrease in output per unit of fishing effort attendant on the increase in total fishing effort. 